Revista Iberoamericana, Vol. LXXI, Núm. 210, Enero-Marzo 2005, 93-104

\title{
LA CULTURA DEL TRATO O LA CASA Y EL ALMA. MARIQUITA SÁNCHEZ DE THOMPSON ${ }^{1}$
}

\author{
POR \\ Graciela BatTicuore \\ Universidad de Buenos Aires
}

\section{UNA INFLUENCIA CIVILIZADORA}

En la Argentina de la primera mitad del siglo xix Mariquita Sánchez encarna la figura de la mujer excepcional, cuya presencia entre los círculos de sociabilidad patricia y luego entre los románticos proyecta hacia ellos una influencia considerada benéfica. Es así que su nombre, tanto como la descripción física y animada de su casa porteña, integra varias páginas de la historiografía argentina o bien irrumpe en las evocaciones nostálgicas de los memorialistas de fines de siglo e incluso sobreviene en el relato intimista de los y las corresponsales contemporáneas. En la Historia de la República Argentina. Su origen, su evolución y su desarrollo político hasta 1852, el historiador Vicente Fidel López compone la imagen de una noche de tertulia en la casa de Mariquita, para dar cuenta del ritmo de la vida porteña entre 1813 y 1814, años en los que el autor reconoce una "transformación de las costumbres en la vida interior de la familia, y en el carácter de los negocios comerciales"(186). Es en ese momento cuando la casa de los Thompson brilla con las luces de la modernidad y el espíritu revolucionario que reúne en torno a la anfitriona a personalidades de la vida política e intelectual, a viajeros de paso por Buenos Aires, a médicos, físicos, botánicos, economistas y pintores que se dan cita en uno de los salones más hermosos y ricamente adornados de la ciudad, animado por la gracia y la belleza encantadora de su dueña. Veamos si no la descripción de López:

\footnotetext{
Abriéronse algunos salones y entre ellos el de Lasala y el de la señora doña María Sánchez de Thompson [...]. Mientras Belmar lucía su intimidad con Benjamín Constant y trazaba los caracteres de su talento y de sus doctrinas ante la atención encantada de los liberales que lo escuchaban, Lozier y Ferrati amenizaban la culta tertulia con pruebas de física y química que iniciaban a los conocimientos naturales a sus contertulianos, y que hacían del salón de la señora de Thompson una verdadera academia de progreso y cultura. Alvear y Larrea primaban entre todos por la rapidez, la originalidad y la audacia de sus
}

\footnotetext{
${ }^{1}$ Este artículo forma parte de un capítulo más extenso titulado: "De la conversación a la escritura. Sobre cómo ser o devenir autora”, incluido en mi tesis doctoral: "Lectoras y autoras en la Argentina romántica. 1830-1870” (mimeo), Graciela Batticuore, Facultad de Filosofía y Letras, Universidad de Buenos Aires.
} 
concepciones; y eran los galanes más favorecidos de las damas que acudían a hacer estrado en rededor de la dueña de aquel templo un tanto profano en que todos abrían su espíritu a las luces del siglo. Allí leía López sus estrofas y algunas veces un niño, Juan Cruz Varela, declamaba sus loas a la patria y a la victoria en que Júpiter hacía el primer papel entre los protectores que nuestra causa tenía en el cielo (135-37).

En este fragmento donde los nombres de algunos vecinos célebres se mezclan con los visitantes extranjeros y los hombres de ciencia, López destaca el espíritu ilustrado y civilizador del salón de Mariquita y, lejos de parangonarlo con cualquier otro ejemplo de sociabilidad americana, lo equipara a los salones del Directorio y el Primer Consulado francés, con lo cual evoca tácitamente el genio y la imagen de Staël. En otro orden de posibles comparaciones es preciso señalar también que las tertulias de Mariquita Sánchez no adoptan el matiz exclusivamente político que a veces suelen tener otras reuniones domésticas de comienzos de siglo en diversos lugares de América Latina, donde la anfitriona hace contactos muy concretos y media entre sus invitados para establecer alianzas facciosas o favorecer la posición social y la carrera política de su esposo. Encontramos algunos testimonios en este sentido, por ejemplo en las Peregrinaciones de una paria de Flora Tristán o bien entre algunas anfitrionas chilenas de la década del 90, como podría ser el caso de Sara del Campo, que antes y durante la presidencia de su esposo (Pedro Montt) mantiene sus tertulias con el objeto de apuntalar el ascenso político de Montt. $^{2} \mathrm{O}$ quizá también un poco más cerca, hallamos ejemplos entre las damas salteñas que forman parte del séquito de los Güemes, los Puch y los Gorriti en el norte argentino. Pero tampoco se debe asimilar el clima de las tertulias de Mariquita con otras veladas más marcadamente literarias, del tipo de las de Juana Manuela Gorriti en Lima hacia 1876-77, que aunque sostienen una aguda reflexión crítica sobre la vida nacional y americana se declaran, al menos explícitamente, ajenas o “neutrales” en su espíritu, al acontecer político. $^{3}$

Las tertulias de Mariquita Sánchez cultivan el espíritu civilizador e ilustrado de una pequeña sociedad aldeana y americana de comienzos de siglo xIx, donde la política forma parte de las preocupaciones de la "gente decente" que participa de este ritual doméstico y cotidiano de sociabilidad. En este sentido resulta interesante considerar los aportes recientes del estudio de Pilar González Bernardo de Quirós sobre la vida asociativa en el Buenos Aires de la época. Y entre sus muchas consideraciones, vale la pena recuperar su advertencia acerca del sentido del término "sociabilidad", tal como es utilizado por la juventud intelectual en el Río de la Plata. Para explicarlo, González se remonta a la genealogía del concepto a comienzos y mediados del siglo xviII, cuando en un artículo de la Encyclopédie se establece "la benevolencia hacia los demás”, la "disposición a hacer el bien” y el "provecho común y general” entre sus definiciones más certeras. A partir de entonces existe una "amalgama entre la noción de lazo racional y el lenguaje de la cortesía”, enfatiza González, y agrega una aclaración más que interesante respecto de la diferencia entre "sociable" y "amable":

\footnotetext{
${ }^{2}$ Véase Vicuña Mackena 96-7.

${ }^{3}$ Véase Batticuore.
} 
el hombre sociable es un verdadero ciudadano. En contraste, el hombre amable es muy indiferente al bien público, no quiere a nadie, agrada a todos y a menudo es menospreciado. Vemos, por lo tanto, la distinción entre una cortesía presuntamente artificial e incluso antisocial y otra constitutiva de las res pública. (87)

Sin dudas es ese sentido de lo sociable que redunda en bien de la ciudadanía el que prima en el trato de Mariquita Sánchez así como en el espíritu de sus tertulias, donde la cortesía y las buenas formas se compatibilizan con un ansia de renovación en las costumbres que tiene en la mira el bien común de la república naciente. Por eso, ya sea a través de la influencia que ella ejerce por medio de su conversación animada en las tertulias o la que despliega más tarde en sus cartas y escritos, Mariquita aparece siempre como una mujer ilustrada y patriota. Una mujer que practica estas virtudes ya sea en el marco de la sociabilidad doméstica o en el compromiso que asume frente a las contingencias de la vida política y, también, a través de los consejos o, dicho de un modo más general, de la moral que inculca a sus hijos y comparte con ellos: "y bien: enseña lo bueno que puedas con calor, pero con dulzura y paciencia, enseña como el siglo lo manda, con racioncinio, con amabilidad"4 es la máxima que le da a su hijo Juan en momentos en que éste reside en Paraná y escribe allí un periódico contra el gobierno de Rosas.

Para profundizar entonces sobre este aspecto singular y constitutivo de la personalidad de esta dama porteña de comienzos de siglo, y para indagar sobre el tipo de influencia que ella es capaz de ejercer, será necesario detenerse en otra descripción de la casa de Mariquita Sánchez evocada esta vez por una dama culta de la época, que tras el exilio de su amiga tiene la ocasión de visitar su mansión hasta entonces desconocida para ella, la cual supera con creces todas sus expectativas:

La casa de Marica Thompson es la más vasta de la ciudad. Es lo más lindo que se puede ver por su construcción en sí y su lujo. Entras y tienes la vista de un patio jardín pavimentado, con una fuente de plantas exóticas y plantas finas, un artístico aljibe de mármol con sombrero de fierros forjados formando glorieta; varias tinajas muy finas. Entras a una recova y subes a un espacioso corredor que abarca toda la parte principal del edificio. No se puede ver nada más lindo: su techo abovedado, cubierto de lienzo pintado; espejos de trecho en trecho y brazos de tres luces en profusión. El antiguo salón todo forrado de brocato amarillo con bellotas dibujadas, y el techo en trabajo de espejos unidos en triángulo, abovedados con varillas de oro; en un ángulo un estrado no muy grande, en el otro el piano, el arpa, una preciosidad con la pintura al barniz [...]. Es una casa distinta a todas las demás en su construcción y distribución. Tiene también una curiosa distribución de aguas por tubos desde los patios, que pasan por medio de llaves a tinas, etc., y otras maravillas. Florencia, la hija, tan fina, tan linda, completa. Sus hijos, preciosos. Dirás que estoy boba; pero es todo así [...]. Aunque estas señoras no fueran como son, por el lugar donde viven, la gente iría como solaz. (Cartas de Mariquita Sánchez, 44) ${ }^{5}$

${ }^{4}$ Carta a Juan Thompson, Montevideo, 8 de mayo de 1840, en Cartas de Mariquita Sánchez (44). En adelante, las citas a otras cartas de Mariquita Sánchez siguen la paginación correspondiente a dicha edición. También las que se refieren a Clara Vilaseca en la introducción o las notas a la obra. ${ }^{5}$ Citado por Clara Vilaseca en nota al pie de su edición de las Cartas de Mariquita... (151) y acompañado por la reproducción del plano de la casa. 
Estos párrafos se encuadran en un pasaje bastante más extenso y pormenorizado, donde Mariquita Nin demuestra no sólo su fascinación por una casa linda, hermosa y diferente a todas las demás sino su propia habilidad para transmitir en la escritura el placer que le ha provocado la visita, relatada como una experiencia única y casi intransferible. Nin se detiene en cada uno de esos objetos preciosos y sofisticados que también evoca López más brevemente en su descripción, así como en los rincones y recovecos de la casa ("tapices", “porcelanas”, “espejos”, “polvos”, “alfileres” y un "juego de peinar”, “ventanas ovales” , "laberintos de recovas" y "jardines unidos por puertas" son algunos de los objetos y espacios que la deslumbran). A partir de entonces esta mujer no puede dejar de imaginarse lo que debió ser la vida social en una casa que a pesar de la ausencia actual de su dueña conserva y transmite todavía la gracia y la magnanimidad de su espíritu.

La luz que ilumina naturalmente los salones a lo largo del día y cuya perdurabilidad aseguran las bujías por la noche; el agua que se desliza con fluidez detrás de las paredes, gracias a una tecnología modernísima para la época, son otros de los aspectos en los que se detiene la corresponsal para señalar una rareza poco menos que esplendorosa, que hace de la casa un verdadero espectáculo civilizador: se trata de un sitio totalmente dispuesto y preparado para recibir. Y aunque Nin no lo dice de este modo, su mirada extasiada sobre la casa avizora el espacio propicio para la existencia de una familia también ilustrada y eventualmente romántica, cuyos valores se asientan en el ideal de una nobleza que no es heredada sino que puede adquirirse a través de la educación. Nin repara en "la luz", precisamente, como uno de los factores que provee a la casa de semejante espectacularidad: "La luz cae en rayos desde arriba. He visto este espectáculo de día y de noche, con sus bujías encendidas, todo fineza de Florencia para que yo lo viera. No me olvidaré de este espectáculo, que no sé decidirme por cual de las horas lo vi más lindo, si de día o de noche”.

No casualmente esta corresponsal recalca la amabilidad y la belleza distinguidas de Florencia y los suyos ("tan fina, tan linda, completa. Sus hijos preciosos. Dirás que estoy boba pero es todo así”). No hay palabras para explicar la belleza verdadera, esa que está dotada de una autenticidad inherente al alma cultivada de las personas. Por eso la noción de familia con la que se maneja Mariquita Sánchez nos recuerda en parte a la que se asoma en las páginas de Amalia. Se trata en este caso de una familia más ilustrada que romántica pero que se concibe como tal no necesariamente por sus parentescos sanguíneos sino sobre todo por sus lazos espirituales, intelectuales e ideológicos. También en esta familia (de la vida real) las mujeres se involucran sentimental y concretamente con la suerte y el destino de la patria, tanto como con la causa de aquéllos con quienes comparten sus ideales. Al menos así lo demuestran las distintas actuaciones e intervenciones de Mariquita y su esposo Martín Thompson en la vida social y política de Buenos Aires entre los años que van de 1810 a 1816, cuando la pareja se pliega al ánimo y la voluntad emancipadora e independentista de la época. ${ }^{6}$ Mientras que Mariquita escribe una famosa carta para peticionar dinero por la compra de armamentos, él participa en las reuniones clandestinas de la Logia Lautaro, que se llevan a cabo en el sótano de su propia casa. No

\footnotetext{
${ }^{6}$ Por ejemplo en agosto de 1810 ambos donan dinero para la expedición al interior organizada por la Junta. Thompson había sido miembro de la Sociedad de los Siete, responsable de la Semana de Mayo, y uno de los doscientos vecinos que asistió al Cabildo Abierto del día 22.
} 
es difícil imaginar que, tal como lo evocan algunos memorialistas de fines de siglo XIX (Wilde, Calzadilla, Gálvez entre los más interesantes) ese espíritu de patriotismo que alienta las ilusiones de la pareja debió formar parte sustancial del clima de ideas y el carácter entusiasta que animaban la conversación diaria en sus tertulias. De hecho, la frecuentación y el contacto con el mundo de letrados, militares y hombres públicos que conforman la élite revolucionaria rioplatense debió intensificar su adhesión republicana. Por eso Mariquita pasaría a la historia sobre todo como la gran dama de la época, la mujer que ofrece el escenario donde se canta por primera vez el himno nacional y se celebran las primeras expresiones del civismo entre los vecinos "decentes". ${ }^{7}$ Pero poco importa realmente si ese episodio simbólico con el cual se recuerda el nacimiento de la patria situándolo en un ámbito doméstico y familiar es o no verídico. Alcanza con que sea verosímil (y simbólico) para la memoria popular y sirve de algún modo para recrear cuál era el ánimo, el contexto y sobre todo el entramado social en el que se producían las transformaciones que marcarían el pasaje de la vida colonial a la república.

De acuerdo entonces con esa noción de familia que surge de una casa ilustrada y rioplatense como la de Mariquita y que se asienta sobre un vínculo más espiritual $e$ ideológico que sanguíneo, puede decirse (y esto lo confirma también la correspondencia de la escritora) que su dueña forma parte no sólo de distintos momentos de la historia nacional sino de diversas familias políticas e intelectuales: la que integra el patriciado argentino de los días de Mayo, cuyo círculo es habitué de las tertulias (Monteagudo, San Martín, Fray Cayetano Rodríguez son amigos personales suyos y por ende visitan la casa); la que conforman los hombres y mujeres allegados al gobierno y la cultura rivadaviana (Esteban de Luca y Juan Cruz Varela por ejemplo, entre los allegados a Mariquita) y, posteriormente, la familia romántica de los proscriptos. Antes, durante y después del exilio compartido con muchos de ellos, el salón es el espacio de realización de una familia así concebida. En esas reuniones distinguidas y amigables donde la conversación gira sin dificultades entre la preocupación por el acontecer político, el rumbo de la vida económica o las lecturas de las últimas novedades literarias europeas y locales se confirman los parentescos ideológicos y estéticos, los intereses comunes, las convicciones compartidas; en otras palabras, las afinidades y complicidades de todo tipo.

\footnotetext{
${ }^{7}$ Existen al respecto diversas versiones. En Mariquita Sánchez. Vida política y sentimental, María Sáenz Quesada recupera la anécdota familiar que afirma que el himno se cantó por primera vez en casa de Mariquita: "Estuvo por aquí Parera, nos entretuvo, contó como se compuso en casa el Himno criollo inspirado por el himno de David que de oído y de pie chapurreaba recordando en el teclado distraído nuestro padre que cantaba de niño", escribe Albina Thompson de Tresserra desde Barcelona, a su hermana Florencia en 1842 (citado por Sáenz Quesada 80) y luego la contrapone a otras versiones que sitúan el episodio en otros ámbitos e instituciones públicas (López, por ejemplo, la sitúa en la sala del Consulado). Más tarde Pastor Obligado afirma en sus Tradiciones... que el Himno Nacional Argentino se cantó por primera vez en casa de Mariquita Sánchez, acompañado por la música de Blas Parera en el arpa. Pero Esteban Buch refuta la idea aduciendo que Obligado se inspira en otra célebre tradición de Palma (creador del género "tradiciones"), quien había escrito antes que el himno peruano se cantó, a su vez, en casa de la limeña Manuela Rávaga y Avella Fuertes de Riglos frente a la presencia del Gral. San Martín. Esta última anécdota habría servido de inspiración a Obligado.
} 
La casa de Mariquita constituye así uno de los núcleos donde se afianzan las relaciones que darán lugar a la sociabilidad asociativa de la que habla por ejemplo Pilar González al referirse a los cruces entre redes privadas y vida pública a comienzos de siglo: las librerías, los gabinetes literarios, las asociaciones son los otros espacios donde esas relaciones se continúan. Incluso, Mariquita formará parte también de esa sociabilidad que transcurre fuera de las casas: al decir de Félix Weinberg ella es una de las pocas mujeres si no la única, que asiste a la inauguración de la librería de Marcos Sastre en 1837 y más de una década antes había contribuido ya, de manera decisiva, a la creación de la Sociedad Filarmónica de Buenos Aires (fundada por iniciativa del maestro italiano Virgilio Rabaglio, en mayo de 1822) (véase también Sáenz Quesada). Su capacidad para reflexionar, discutir e intercambiar opiniones sobre asuntos relativos al acontecer político o a las novedades en materia de artes, música, libros y literatura la coloca en una posición de camaradería e igualdad con los interlocutores de los diversos círculos de los que forma parte. Por eso, conviene recordar no sólo que el matrimonio Thompson apoyó e integró el sector político más radicalizado de los revolucionarios que pujaban por la Independencia a comienzos de la década del 10 o bien que cuando Mariquita se casa con Mendeville estrecha vínculos con la diplomacia francesa y europea que visita su casa a diario sino también que poco después sería convocada por Bernardino Rivadavia para presidir la Sociedad de Beneficencia, en virtud, precisamente, del reconocimiento a su perfil ideológico y su capacidad para "influenciar" favorablemente a los hombres y mujeres de la época. Es el respeto y la autoridad que inspira Mariquita entre sus amigas y conocidas lo que logra reunir en poco tiempo alrededor suyo al que será el primer grupo de mujeres dispuestas a trabajar en una institución pública y dependiente del Estado. ${ }^{8}$ Esta iniciativa de Rivadavia constituye un reclamo inédito hasta entonces, para que las mujeres de la élite intervengan de manera directa en un organismo de la esfera pública considerado adecuado para ellas. Desde luego, la invitación marca un hito (y hasta un giro) en las relaciones entre género y política en la Argentina de primera mitad de siglo xIx y resignifica, en parte, el tipo de influencia que se espera ahora de las mujeres (tengamos en cuenta que la Sociedad no cerrará sus puertas durante el gobierno de Rosas, aun cuando éste le niegue casi toda su colaboración). El discurso inaugural de Rivadavia en la sesión de apertura, en febrero de 1823, recala una vez más en el reclamo de esa influencia civilizadora de las mujeres para justificar su incorporación a un organismo oficial. Pero es ésta una influencia femenina que comienza a ejercitarse desde el interior mismo de una institución estatal y no sólo a través de la familia, como hasta entonces se había esperado que lo hicieran.

\footnotetext{
${ }^{8}$ En este sentido es interesante recordar que como ha señalado Meyer-Arana, Mariquita no había sido invitada en primera instancia por Rivadavia, quien hizo una convocatoria abierta a las mujeres de la clase alta. Ante la negativa o la reticencia de muchas de ellas, que probablemente no se animaron a ser las primeras en ejercer una actividad pública de tanta responsabilidad (o bien temieron echarse en contra a la iglesia, que obviamente veía la iniciativa con malos ojos), Rivadavia acude a Mariquita, confiando en que ella sí puede concitar la adhesión necesaria entre sus amigas y conocidas. De hecho, en febrero de 1823 habrá logrado reunir al primer cuerpo de mujeres que conforman la Sociedad. Véase Meyer-Arana Las primeras trece. Para una aproximación a la historia de la Sociedad de Beneficencia y su ubicación durante el rosismo, véase del mismo autor: Rosas y la Sociedad de Beneficencia.
} 
Como vemos, Mariquita transita el pasaje que va del salón doméstico a las instituciones públicas. Me interesa explorar sobre todo su protagonismo en el primero de estos dos ámbitos, por ser ese el sitio donde se estrechan los vínculos y se adquieren las destrezas que habilitan otras intervenciones y actuaciones posteriores. El epistolario de Mariquita está marcado por la impronta de la salonnière, que antes o durante el exilio ejerce esta suerte de oficio con natural distinción. Su imagen encaja perfectamente en el cuadro de esa casa refinada y "espectacular" que asombra y maravilla a sus contemporáneos. Sin embargo, lo que las cartas dejan ver también -y es en esto en lo que me interesa ahora detenerme- es que la sociabilidad representa para ella no sólo un quehacer gustoso y placentero sino también un trabajo que no puede suspenderse o postergarse debido al desgano y casi por ninguna otra razón. La necesidad de cumplir con las visitas y las reuniones previstas y necesarias para las "gentes decentes" organizan el tiempo y los esfuerzos de esta dama ilustrada y rioplatense. A menudo ella se lamenta de esto en las cartas a su hija, que son un verdadero manual de consejos y enseñanzas acerca de cómo debe llevar adelante su vida o de cuáles son las obligaciones ineludibles para una señora de buena sociedad. En la correspondencia con Florencia la casa es el gran tema de conversación. Como ha señalado Cristina Iglesia, allí se reiteran las quejas por la casa perdida en el destierro y también los esfuerzos por recuperar algo de ese mundo esplendoroso y rutilante en el que solía moverse, aunque más no sea a través de los “pedacitos rotos de un jarrón” que difícilmente podrá remendarse. Pero lo que estas cartas demuestran no es sólo el ansia de Mariquita por asegurarse en el exilio el confort y las comodidades de su vida porteña, así como el contacto y la proximidad diaria con los hijos a los cuales extraña, sino que ellas ponen de relieve, también, su deseo de recrear en otra parte el marco de aquélla belleza imprescindible para la familia ilustrada. ${ }^{9}$ Recomponer la casa en el exilio significa entonces restaurar el ideal de una felicidad alterada por el compromiso político, que sólo puede realizarse plenamente si se reconstruye también, aunque sea mínimamente, el escenario adecuado para las conversaciones y encuentros con amigos y conocidos. De modo que si bien Mariquita llega a veces a manifestar la ilusión de habitar una casita rústica y aislada de todos, el sueño de la "casa grande” y capaz de albergar a los hijos, los amigos y los visitantes célebres en medio de un ámbito recoleto y lujoso es una necesidad más auténtica y acorde con su personalidad. En una frase breve dispensada a su hija, Mariquita sintetiza la clave de todos sus comportamientos íntimos y sociales: "la casa es la vida”, asegura. Y entonces tanto los placeres como los esfuerzos y los sacrificios se encaminarán a sostener el ritmo animado y a ratos exigente que demanda su protagonismo en sociedad. La casa a la que se refiere esta corresponsal, la que guía en su mente el espíritu de la mansión lujosa de Buenos Aires y también las moradas más austeras aunque igualmente cuidadas del destierro, no es la casa cerrada en los límites de una familia estrictamente unida por lazos y parentescos sanguíneos, no es la casa donde

\footnotetext{
${ }^{9}$ Son innumerables las referencias de todo tipo al esfuerzo por llevar adelante la casa: las complicaciones con los criados, la carencia de objetos y alimentos variados como consecuencia del sitio de Montevideo, el arduo trabajo de armar y desarmar las valijas y las casas antes y después de los viajes recuerdan los lamentos y nostalgias que se deslizan también en el interior de la correspondencia de otros exiliados de la época.
} 
habitan los esposos y los hijos sino una casa ilustrada, colmada de amigos, relaciones y vínculos sociales, donde los hijos son parte de un entramado familiar más extendido.

\title{
RETRATOS Y AUTORRETRATOS
}

Encontramos en las cartas de Mariquita múltiples retratos (fugaces pero nítidos) de la mujer conversadora y su capacidad de influir como tal entre quienes la rodean. Este rasgo la lleva a ser constantemente reclamada y agasajada por aquéllos que reconocen y halagan en ella una cualidad tan singular, incluso en el ámbito de una sociabilidad algo exótica y cortesana como la de Río de Janeiro, donde Mariquita reside durante algunos meses (entre agosto de 1846 y febrero de 1847 aproximadamente) mientras espera la ocasión finalmente frustrada de partir hacia Europa. A Mariquita le gusta formar parte de esta cultura con matices monárquicos, que la convierte en el centro de todas las miradas y los halagos y le devuelve al menos por un rato las comodidades y los lujos propios de su antigua posición. En una de las primeras cartas que le envía a su hija Florencia desde Río, describe con placer las comodidades palaciegas de sus allegados y comenta los innumerables obsequios de los que es objeto:

\begin{abstract}
Los amigos del país tienen gusto en obsequiarme y me mandan coche también. Están empeñados en presentarme a la Emperatriz. No sé si iré. ¿ ¿Te figuras a Seña Vicenta con cola y plumas en la cabeza? Pues aquí, amiga, la Señora Esposa del Encargado de Negocios de Francia en Quito está en el primer rango, y después están contentísimos todos conmigo porque encuentro esto divino, y les hablo en portugués. Si nos oyeras estudiar unas con otras, las de Vernet, te morías de risa: ¿La señora lo ha pasado muito bien? Muito obligada. Madame Mendeville e muito espiritual, muito graciosa. Yo les digo que en cuanto me den un bocadiño de terra, ya me quedo. Hay unas bromas sobre esto: que me van a hacer un palacio en una montaña. En fin lo paso estimada y muy obsequiada. Sería una ingrata si me quejase. (129; Río de Janeiro, 1/8/46)
\end{abstract}

En las cartas escritas desde Río, Mariquita se mueve constantemente entre la complacencia de una dama que se reencuentra con los lujos y las comodidades que considera necesarios para su persona y la ironía con la que pretende tomar una sutil distancia de esta otra gente fina y educada pero entre la cual su talento resplandece sin comparación. Ni siquiera la Emperatriz se salva de los chistes que reservadamente le dispensa Mariquita ya antes de conocerla, representándosela imaginariamente "con cola y plumas en la cabeza”. Aunque después de haberla tratado, admitirá que ella es "muy amable” y que toda la alta sociedad de Río vive con lujo pero también con "sencillez” y "humildad". No obstante, la estadía en Brasil debe interrumpirse irremediablemente porque en ese mundo donde las cartas y las noticias de Buenos Aires se hacen esperar más de la cuenta, una dama ilustrada y comprometida en los avatares de la política de su país no puede sobrevivir sin angustias. Primero Mariquita "se aburre” un poco de la vida relajada y algo tediosa de Río y luego se inquieta porque no logra saber qué es lo que pasa más allá de las fronteras ni mantener al día su correspondencia ("Es probable que en la primera ocasión que se me presente me vaya a Montevideo. Aquí carezco mucho de noticias de todo, de mi familia, de mis intereses” (130, Río de Janeiro, 23/9/46). En esta 
necesidad imperiosa de saber y conocer los hechos inminentes del acontecer diario de su patria es donde radica buena parte de su distinción, su singularidad, el elogio que los otros hacen de su persona pero también la conciencia y el aprecio que ella tiene de sí misma. Mariquita se reconoce como una mujer distinta a la mayoría y dispuesta a hacer grandes esfuerzos y sacrificios para sostener la reputación conseguida hasta el momento. Es este y no otro el legado, la herencia que ella guarda para sus hijos. Solamente con Florencia comparte una suerte de confesión o de consejo, cada vez que le advierte sobre la necesidad de parecer (y no sólo de ser) virtuosa y refinada. Los vestidos, los gestos, los movimientos, la elegancia en el trato, las diligencias diarias con las que procura agradar y mantener contentos a los amigos y conocidos ocupan el tiempo y constituyen la actividad principal de una dama que se precia.

Desde luego, el dinero no es una motivación por sí mismo pero sí un instrumento necesario para llevar adelante esta clase de vida y por eso la preocupación económica es un tópico recurrente en las cartas. Además de ocuparse del cobro de las rentas de su casa porteña, de la compra y venta de muebles y objetos que aporten algún ingreso extra a la siempre raleada economía doméstica, Mariquita sueña con ganarse la grande, con heredar a Mendeville, con viajar a Europa. Estos son sueños que no se concretarán jamás pero que la ayudan a sobrellevar las dificultades y a disfrutar de las satisfacciones que sí obtiene cada vez que confirma su liderazgo en sociedad, sea porque es mimada y agasajada "por todos" o bien porque al juzgar sus modales y comportamientos, los otros creen que ella ha estado previamente en Europa y se ha codeado allí con las personas más distinguidas de la sociedad, de quienes ha aprendido los modos y maneras que tiñen su conducta: “yo los dejo creer”, alega Mariquita con orgullo. Y la satisfacción puede ser a veces mayor si es una francesa auténtica quien la confunde con una compatriota: "estoy por escribirle (a Mendeville) que la Condesa Waleska decía que no podía creer que yo no era francesa la primera vez que estuve con ella” (162), responde a Florencia el 4 de setiembre de 1847 atajando una mala pasada de su esposo, que le aconseja no ir a Francia porque cree que la vida allí no será de su agrado. ${ }^{10}$

Ser y parecer son las dos caras de una misma moneda que deben reflejar cultura, nobleza de espíritu, distinción, y que emparentan a esta mujer rioplatense con otras damas ilustradas europeas entre las cuales ella elige por sí misma los parentescos deseables. En una carta enviada a Juan María Gutiérrez, Mariquita comenta la lectura de un retrato de Guizot sobre Mme. de Récamier que su amigo le hiciera llegar previamente. Se asoman varias cuestiones interesantes en esas líneas, en primer lugar porque ellas ofrecen una idea de la admiración que siente la corresponsal por el pasado europeo y, particularmente, por la forma de acceso al conocimiento que todavía podía obtenerse en la cultura de los salones franceses de comienzos de siglo. Mariquita les rinde su tributo cuando al referirse a Juliette Récamier afirma que "en el mundo en que [ella] vivió se aprendía aún más que en los libros” (337, sin fecha). Se refiere desde luego a la posibilidad del contacto con las grandes

\footnotetext{
${ }^{10}$ La Condesa Waleska es nuera de Napoleón I y había sido enviada por el gobierno francés para establecer negociaciones con Rosas. Como señala Clara Vilaseca en nota a las cartas de Mariquita Sánchez, durante su estadía en Buenos Aires la Condesa se hizo muy amiga de Mariquita (y también de otros contemporáneos como José Mármol), a tal punto que dio a luz en su casa.
} 
personalidades de la cultura y la literatura, que comparten y enseñan su arte a través de la conversación, el trato, la lectura en voz alta en el ámbito de una domesticidad "mundana” y culta. ${ }^{11}$ Pero también, Mariquita aprovecha la ocasión para revelar "un secreto” que a sus ojos debilita o desmerece en parte los elogios a esa célebre salonnière, afirmando que ella no era, como se cree, “una gran inteligencia” y que su belleza le debía casi todo a la frialdad con la cual esta mujer observaba el mundo y se relacionaba con su época. Mariquita es categórica en el diagnóstico: “[Récamier] era un ser incompleto y no podía sentir las pasiones, la desesperación de una infamia o una ingratitud. Su vida era un arroyuelo suave, sin borrascas y su belleza se conservaba así mejor, porque nada podía alterarla” (337).

Récamier carece de la pasión que anima a una amiga y contemporánea suya que también descolla entre la sociabilidad europea de comienzos de siglo y con la cual Mariquita se identifica con más facilidad. Me refiero a Mme. de Staël, cuyo valor para enfrentar las adversidades a las que la vida y la política de la época la someten despiertan su admiración. Recordemos, no obstante, que Récamier fue amiga íntima de Staël y, como ella, abrió salones en diversas ciudades de Europa: en París, Roma y Florencia, donde a mediados de la década del 20 era visitada y celebrada por grandes personalidades, como Benjamin Constant (que se enamoró de ella perdidamente), Stendhal o Balzac. También la literatura y la presencia de Chautebriand (quien fuera su amante durante varios años) animó las veladas de Juliette, que se ocupó en ellas de avivar el calor de su público. Pero como sostiene Verena von der Heyden-Rynsch, a diferencia del salón de Staël, el de su amiga se mantuvo siempre ajeno a la política y se limitó, en cambio, a ofrecer un espacio de resonancia ilustrada para el arte, la literatura y el decoro. La vida en el salón de Récamier adopta así el clima previo a la revolución, por lo que llegó a ser comparado por Lamartine con una monarquía (véase Los salones europeos. Las cimas de una cultura femenina desaparecida). Sin duda, es este desapego del compromiso con la política y la república el que provoca los reparos de Mariquita contra Mme de Récamier y la inclina del lado de Staël. Para validar e ilustrar mejor sus juicios sobre aquélla, la corresponsal remata estas reflexiones con una "anécdota espiritual” que coloca a ambas salonnièrs junto a un amigo común, el cual tras dispensar a las señoras muchos cumplidos, es puesto en el aprieto de tener que brindar una respuesta que lo compromete.

Cuenta Mariquita que Staël le pregunta a Monsieur Talleyrand a quién salvaría él la vida en caso de que ellas dos se estuvieran ahogando al mismo tiempo. A lo que Talleyrand responde sin demora ni titubeos: “a Mme Récamier, porque usted nadaría sola. ¡Vea usted qué gracioso modo de lisonjear a las dos! ¡Ay, amigo, qué encanto es la sociedad de gente fina! Yo he gozado mucho en ella, y así, siento más mi soledad!” ( 337). Desde luego, la relevancia de la anécdota trasciende este comentario final con el cual la corresponsal aprovecha para subrayar su admiración por esa gente sutil y educada, que sabe cómo halagar a las personas aún cuando está señalando en ellas un defecto o debilidad. El objeto principal de esta anécdota apunta en cambio a resaltar la admiración por el carácter o el

\footnotetext{
${ }^{11}$ El concepto de "mundanidad” ha sido utilizado con frecuencia por diversos autores/as que se ocupan de analizar las prácticas de sociabilidad en los siglos XVI, XVII y XVIII. De fácil alcance, puede consultarse Dulong.
} 
temple resuelto y apasionado de una mujer como Staël, cuya fortaleza para enfrentar las adversidades de la vida se complementa en lo anímico con la sabiduría adquirida a través de la educación del trato y los libros, haciendo de ella una mujer íntegra. Con esta anécdota Mariquita se aleja de lo que claramente considera una belleza sin gracia, un espíritu ilustrado pero sin compromisos ni entusiasmo, y toma partido por la pasión enérgica de una mujer con corazón. Es con Staël y no con Récamier con quien Mariquita se identifica más y, como vemos, no pierde ocasión de hacérselo saber a sus amigos.

En estas y otras cartas dirigidas a personalidades de relieve en la escena de la época, la corresponsal ofrece así la imagen de una mujer ilustrada y comprometida con su tiempo, una mujer cuyo perfil americano se define a la vez en la atracción por determinados modelos europeos y la impronta que irremediablemente dejan en ella los acontecimientos o vicisitudes de la vida política y cultural a la que pertenece.

\section{BibliografíA}

Batticuore, Graciela. El taller de la escritora. Veladas Literarias de Juana Manuela Gorriti. Lima-Buenos Aires (1876/7-1892). Rosario: Beatriz Viterbo, 1999.

Buch, Esteban. O juremos con gloria morir. Historia de una épica de Estado. Buenos Aires: Sudamericana, 1994.

Dulong, Claude. “De la conversación a la creación”. Historia de las mujeres. Del Renacimiento a la Edad Moderna. Dirigida por Arlette Farge y Natalie Zemon Davis. Madrid: Taurus, 1992. 424-51

González Bernaldo de Quirós, Pilar. Civilidad y política en los orígenes de la Nación Argentina. Las sociabilidades en Buenos Aires, 1829-1862. Buenos Aires: Fondo de Cultura Económica, 2001.

Iglesia, Cristina. “Contingencias de la intimidad: reconstrucción epistolar de la familia del exilio”. Historia de la vida privada en la Argentina. País antiguo. De la colonia a 1870. Dirigida por Fernando Devoto y Marta Madero. Buenos Aires: Taurus, 1999. 203-23.

López, Vicente Fidel. Historia de la República Argentina. Su origen, su revolución y su desarrollo político hasta 1852. Tomo V. Buenos Aires: Casavalle, 1886.

Meyer-Arana, Alberto. Las primeras trece. Buenos Aires: Editorial Pesce, 1923. Rosas y la Sociedad de Beneficencia. Buenos Aires, Imprenta de Gerónimo Pesce, 1923.

Obligado, Pastor. Tradiciones Argentinas. Barcelona: Montaner y Simón, 1903.

Sáenz Quesada, María. Mariquita Sánchez. Vida política y sentimental. Buenos Aires: Sudamericana, 1995.

Sánchez de Thompson, Mariquita. Cartas de Mariquita Sánchez. Compilación, prólogo y notas de Clara Vilaseca. Buenos Aires: Peuser, 1952.

Recuerdos del Buenos Aires Virreynal. Prólogo y notas de Liniers de Estrada. Buenos Aires: Editorial Ene, sin fecha.

Vicuña Mackena, Manuel. La belle époque chilena. Alta sociedad y mujeres de elite en el cambio de siglo. Santiago: Sudamericana, 2001. 
Von der Heyden-Rynsch, Verena. Los salones europeos. Las cimas de una cultura femenina desaparecida. Barcelona: Península, 1998.

Weinberg, Félix. El salón literario de 1837. Buenos Aires: Hachette, 1977. 